\title{
Supplemental information: Structural evolution in photodeposited nickel (oxy)hydroxide oxygen evolution electrocatalysts
}

\author{
Martin A.W. Schoen, ${ }^{\dagger}$ Nicholas M. Randell, ${ }^{\dagger}$ Oliver Calderon, ${ }^{\dagger}$ Santiago Jimenez \\ Villegas, ${ }^{\dagger}$ Zachary Thomson, $^{\dagger}$ Roman Chernikov, $^{\ddagger}$ and Simon Trudel ${ }^{*, \dagger}$ \\ †Department of Chemistry and Institute for Quantum Science and Technology, University of \\ Calgary, 2500 University Dr NW, Calgary, AB T2N 1N4 Canada \\ $\ddagger$ BIOXAS Beamline, Canadian Light Source, 44 Innovation Boulevard, Saskatoon, SK, S7N 2V3, \\ Canada \\ E-mail: trudels@ucalgary.ca
}




\section{Experimental Section}

Chemicals and substrates $\mathrm{Ni}(\mathrm{II})$ 2-ethylhexanoate (Ni(2-ethex) $2,78 \%$ in mineral spirits) was purchased from STREM Chemicals, methyl-isobutyl-ketone (MIBK) was purchased from Alpha Aesar, potassium hydroxide obtained from EMD Millipore. All were used as-receievd without further purification. $99 \% \mathrm{NiO}$ powder for XRD and EXAFS standards was purchased from Alpha Aesar. Fluorine-doped tin oxide (7 $\Omega / s q$.) on glass substrates (FTO) were acquired from Hartford Glass Company. FTO substrates were cleaned by 5 minute sonication in acetone, which was not allowed to dry and rinsed off with isopropanol and subsequently dried in $\mathrm{N}_{2}$. $\mathrm{SiO}_{2}$ (50 nm) / Si subtrates were prepared by cleaning in-house cut Si(100) wafers (Universiy Wafers, B-doped, $500 \mu \mathrm{m}$ thick), using the same cleaning procedure as for the FTO substrates. A thermal oxide layer of approximately $50 \mathrm{~nm}$ thickness (verified by ellipsometry) was produced by annealing substrates in air for $5 \mathrm{~h}$ at $1000^{\circ} \mathrm{C}$ in a furnace.

Fe-free KOH was prepared following previously reported methods. ${ }^{1}$

Thin film deposition Amorphous $\mathrm{NiO}_{x}$ films were deposited by ultraviolet-initiated photochemical deposition, as previously reported. ${ }^{2-4}$ Briefly, Ni(2-ethex) 2 was diluted to 15 wt\% in MIBK and the resulting precursor solution spin coated (Laurel, $3000 \mathrm{rpm}, 60 \mathrm{~s}$ ) on clean FTO substrates, or $\mathrm{SiO}_{2}(50 \mathrm{~nm}) / \mathrm{Si}$ substrates. These films were then irradiated with a UV light (Atlantic UV lamp model GPH893T5VH/HO/4PSE High Ozone, $\lambda=185 \mathrm{~nm}$ and $254 \mathrm{~nm}$ ) for $24 \mathrm{~h}$, ensuring a complete decomposition of the ligands, producing a homogeneous thin film of $\mathrm{NiO}_{x}$. The films were used as-prepared (no anneal), or annealed in air at temperatures ranging between 100 and $600{ }^{\circ} \mathrm{C}$ for samples on FTO substrates, and up to $1000{ }^{\circ} \mathrm{C}$ for samples on Si substrates. Samples are labeled as Ni-AP for the as-prepared samples and as Ni-100, Ni-200, Ni-300, etc. for the annealed samples.

X-ray diffraction (XRD) XRD was performed with a Bruker D8 Advance Eco with a Cu $\mathrm{K}_{\alpha}$ tube $(\lambda=1.5406)$ in the vicinity of the (111) and (200) peaks for $\mathrm{NiO}\left(2 \theta=36-46^{\circ}\right.$, step width $0.04^{\circ}$, and $3 \mathrm{~s}$ averaging per step). The crystallite size $d_{\mathrm{cr}}$ was estimated using the Scherrer equation $^{5}$ 


$$
d_{\mathrm{cr}}=\frac{K \lambda}{\beta \cos \theta}
$$

where $K$ is the shape factor (a value of 0.9 was used), $\lambda$ is the $x$-ray wavelength, $\beta$ is the instrumentbroadening corrected full width at half maximum (FWHM) of the XRD peak, and $\theta$ is the Bragg angle. The XRD peak is fit with a Lorentzian function to extract the peak's FWHM. The FWHM is corrected for instrument broadening, which is determined as the FWHM of a bulk powdered $\mathrm{NiO}$ sample $\left(\beta=\beta_{\text {measured }}-\beta_{\mathrm{NiO}}\right)$. Error bars are estimated from the $2 \sigma$ confidence interval of the Lorentzian fits with an additional $10 \%$ error from the uncertainty in shape factor $K$ which typically ranges from 0.8 to 1 for similar samples. ${ }^{6}$

Ultraviolet-visible (UV-vis) spectroscopy UV-vis spectroscopy was performed with a Cary 5000 spectrometer equipped with a DRA-2500 diffuse reflectance attachment between $0.6 \mathrm{eV}$ and $5 \mathrm{eV}$. Band gaps were determined following a Tauc analysis. ${ }^{7}$ Errors are estimated from $2 \sigma$ confidence intervals of the linear fit to the Tauc plot.

X-ray absorption spectroscopy (XAS) X-ray absorption spectra at the Ni K-edge were collected at the BioXAS beamline (Main Endstation) of the Canadian Light Source. A Si(220) double crystal monochromator was used. X-ray fluorescence spectra were recorded with a 32-channel energy-discriminating Canberra Ge fluorescence detector. Spectra were acquired from $150 \mathrm{eV}$ below the absorption edge to $k=14 \AA^{-1}$. Two series of samples were measured: first, annealed $\mathrm{NiO}_{x}$ films; second, a series of corresponding electrochemically pre-treated films. For the latter series the samples were put in the electrochemical cell described below and held at a potential of $1.9 \mathrm{~V}$ vs. RHE ( $\approx 15 \mathrm{~mA} \mathrm{~cm}{ }^{-2}$ ) for $120 \mathrm{~s}$, rinsed, dried off, and measured ex situ. These post operando (PO) measured samples are labeled as Ni-AP-PO, Ni-100-PO, Ni-200-PO, etc. Samples were measured within $3 \mathrm{~h}$ of electrochemical treatment, since visible discoloration of the treated samples occurred after $8 \mathrm{~h}$ in ambient conditions. Additionally, spectra of powdered $\mathrm{NiO}$ and $\mathrm{Ni}(\mathrm{OH})_{2}$ were recorded as comparative reference spectra. All spectra were analyzed using the Demeter software package version $0.9 .26,{ }^{8}$ after normalization and flattening. The energy was calibrated using the absolute energy list by Kraft, ${ }^{9}$ using a Ni foil. The following data 
processing settings were used: pre-edge range $-150 \mathrm{eV}$ to $-50 \mathrm{eV}$, normalization range $200 \mathrm{eV}$ to $700 \mathrm{eV}, R_{\mathrm{bkg}}=1.1 \AA$, spline range $k=0-14 \AA^{-1}$, and Fourier transform in $k$ from 3 to $12 \AA^{-1}$. Scattering paths were calculated using FEFF6 ${ }^{10,11}$ based on a structural model of NiO. Fits are weighted by $k$ and $k^{3}$. Error bars for the extracted parameters are the standard errors calculated by Artemis.

X-ray photoelectron spectroscopy (XPS) X-ray photoelectron spectroscopy (XPS) was performed using a Kratos Analytical XPS spectrometer (nanoFAB Fabrication and Characterization Centre, University of Alberta) with a monochromatic $\mathrm{Al} \mathrm{K}$ source $(\lambda=1486.6 \mathrm{eV})$ and a $2 \mathrm{~mm}^{2}$ probing area. All spectra were analyzed using CasaXPS software (http://www.casaxps.com/). Spectra were corrected by calibrating all peaks to the adventitious C 1s peak signal at $284.5 \mathrm{eV}$. A Shirley-type background was used, and curve fitting was performed using a combination of Gaussian and Lorentzian [GL(85)] profiles. Fitting of the high-resolution Ni spectra was only performed on the $\mathrm{Ni} 2 \mathrm{p}_{3 / 2}$ peak following the method outlined in Ref. 12. $\mathrm{NiO}, \mathrm{Ni}(\mathrm{OH})_{2}$, and $\mathrm{NiOOH}$ peaks with constraint fit parameters ${ }^{12}$ are used to model the data.

Electrochemistry Electrochemical measurements were carried out using a CH Instruments 660D potentiostat. A Pt mesh was used as a counter electrode and a saturated $\mathrm{Ag} / \mathrm{AgCl}$ electrode used as a reference electrode, sitting in a Luggin cappillary. The supporting solution is $1 \mathrm{M} \mathrm{KOH}$ aqueous solution. Fe-free $\mathrm{KOH}$ was used to avoid electrolyte impurities in the films. ${ }^{1,13}$ Calibration of the $\mathrm{Ag} / \mathrm{AgCl}$ (sat. $\mathrm{KCl}$ ) electrode against a $1 \mathrm{mM}$ aqueous solution of $\mathrm{Na}_{4}\left[\mathrm{Fe}(\mathrm{CN})_{6}\right](E=0.361 \mathrm{~V}$ vs NHE$)$ was regularly performed throughout the study thus obtaining potential vs NHE. The uncompensated resistance $R$ was measured using high-frequency impedance measurements. The $i R$-corrected overpotential $\eta$ can then be calculated ${ }^{3}$ as $\eta=$ $E_{\text {applied vs NHE }}+0.059 \cdot \mathrm{pH}-i R-1.23$.

All measurements are reported as current densities, normalized by the geometric surface area. Unless specified otherwise, all potentials are against the reversible hydrogen electrode (RHE). Cyclic voltammetry (CV) was carried out at two different sweep rates of 0.1 and $0.01 \mathrm{~V} \mathrm{~s}^{-1}$. CVs were run until the catalyst was stable. $\eta$ at catalytic onset and at a current density of 
$10 \mathrm{~mA} / \mathrm{cm}^{2}$ were then determined. Catalytic onset was defined as the start of the Tafel region. Step-wise voltammetry was carried out in the linear Tafel region. At each step the catalyst was given $40 \mathrm{~s}$ to stabilize before measuring. The Tafel slope was then extracted from the linear section of the $\log (j)$ vs. $\eta$ plot. All electrochemical measurements were measured in triplicate and reported values are the average of these measurements. Errors are estimated from the $95 \%$ confidence intervals $(2 \sigma)$ of the triplicate results.

The double layer capacitance $C_{\mathrm{dl}}$ was determined by first running CVs from 0.9 to $2.4 \mathrm{~V}$ vs RHE until a steady state is reached and then measuring CVs in the non-faradaic region before any catalytic activity at scan rates $v$ ranging from 0.005 to $0.1 \mathrm{~V} \mathrm{~s}^{-1} . C_{\mathrm{dl}}$ is then calculated from the slope of $j$ at $0.075 \mathrm{~V}$ vs $v$, via $j=C_{\mathrm{dl}} v .{ }^{14}$ Error bars are calculated from the $2 \sigma$ confidence intervals of the linear fit.

Electrochemical impedance spectroscopy (EIS) was performed at a potential of $1.7 \mathrm{~V}$ vs. RHE at frequencies between $10^{6} \mathrm{~Hz}$ to $0.01 \mathrm{~Hz}$ with 10 points per decade. Spectra were analyzed by the Zview 2 software by modelling the data by the equivalent circuits shown in Fig. S12b.

Electrochromism Samples were measured in-situ submerged in a $1 \mathrm{M} \mathrm{KOH}$ solution in a quartz cuvette, with the Pt mesh counter electrode and Ag/AgCl(sat'd) reference electrode submerged in the cuvette and an adjacent Luggin cappilary, respectively. Spectra in the visible range (350 $\mathrm{nm}$ to $800 \mathrm{~nm}$ ) were taken in the following order: before applying a current, after running approx. $10 \mathrm{CVs}\left(0.9 \mathrm{~V}\right.$ to $2.4 \mathrm{~V}$ vs RHE at 0.1 and $\left.0.01 \mathrm{~V} \mathrm{~s}^{-1}\right)$, at the potential of the first oxidation peak, at $1.9 \mathrm{~V}$ vs RHE, at $2.4 \mathrm{~V}$ vs RHE, at open current potential, and after running a regeneration cycle. $100 \%$ transmission for these measurements was defined as the transmission of the KOH-filled quartz cuvette. Regeneration cycles consisted of 3 CVs from 0.9 to $1.1 \mathrm{~V}$ vs RHE at $0.01 \mathrm{~V} \mathrm{~s}^{-1}$, recovering maximal transmission after applying the potential.

Kinetic measurement were taken by measuring transmission over time at $450 \mathrm{~nm}$ and applying a single voltage step to the potential of the first oxidation peak, $1.9 \mathrm{~V}$ vs RHE, or $2.4 \mathrm{~V}$ vs 
RHE and turning off the potential once a steady state is achieved. Similarly, transmission is measured during CVs from 0.9 to $2.4 \mathrm{~V}$ vs RHE at $0.1 \mathrm{~V} \mathrm{~s}^{-1}$ and $0.01 \mathrm{~V} \mathrm{~s}^{-1}$. 


\section{Figures}

\section{Optical properties}

Diffuse reflectance spectra and the Kubelka-Munk parameter for the direct band gap $(F(R) h v)^{2}$ are plotted in Fig. S1a for Ni-100, Ni-300, and Ni-600 on Si wafers. The spectra show a single decrease in reflectivity (increase in absorption $\approx(F(R) h v)^{2}$ ) for each sample, consistent with a band gap corresponding to that energy. Each sample exhibits an additional absorption peak at approximately $1 \mathrm{eV}$, that is independent of $T_{\text {anneal }}$ (data not shown), which we attribute to the $\mathrm{Si}$ substrate. The band gaps increase almost linearly with $T_{\text {anneal }}$ from $3.8 \mathrm{eV}$ for Ni-AP to $>5.7 \mathrm{eV}$ for Ni-600 (Fig. S1b). The range of our instrumentation is limited to $5 \mathrm{eV}$ therefore, we can only give a lower limit for the band gaps above $5 \mathrm{eV}$. Our determined band gaps present a significant blue shift compared to literature values, where band gaps range from $3.2 \mathrm{eV}$ to $4.5 \mathrm{eV}^{15,16}$ for nickel oxides depending on sample deposition technique and substrate. Additionally, computations have shown that relatively small changes in stoichiometry significantly influence the band gap. ${ }^{17}$ However, we have not found precedence for the exceedingly large band gaps of our sample series. At this point the origin of this discrepancy is not know and warrants further investigation, which is beyond the scope of this present work.

a.

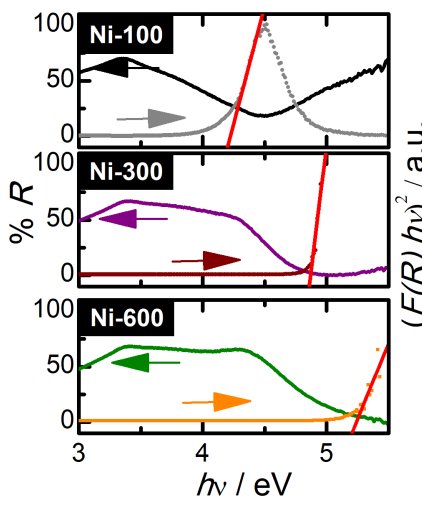

b.

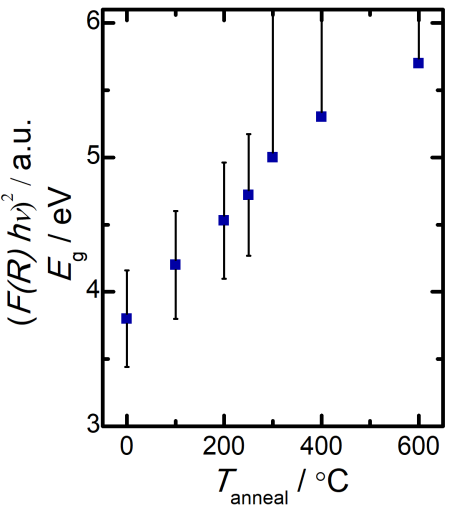

Figure S1: a. UV-Vis diffuse reflectance spectra for Ni-100, Ni-300, and Ni-600; Diffuse reflectance on lhs axis and $(F(R) h v)^{2}$ on rhs axis. b. determined band gap plotted against annealing temperature. 


\section{X-ray diffraction}

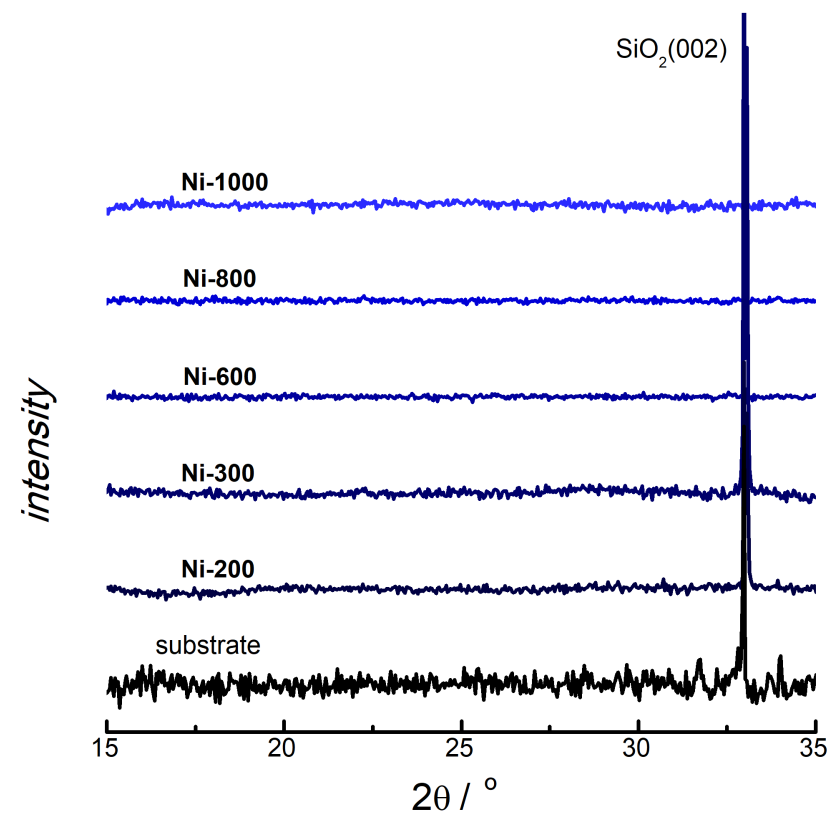

Figure S2: XRD diffraction patterns froom $2 \theta=15 \circ-35 \circ$. Samples are denoted in the plots. Additionally, the diffraction pattern of the $\mathrm{Si} / \mathrm{SiO}_{2}$ substrate is shown. The peak at approximately $33 \circ$ is attributed to the $\mathrm{SiO}_{2}(002)$ diffraction peak of the substrate. No other peaks were measured. 


\section{X-ray photoelectron spectroscopy}

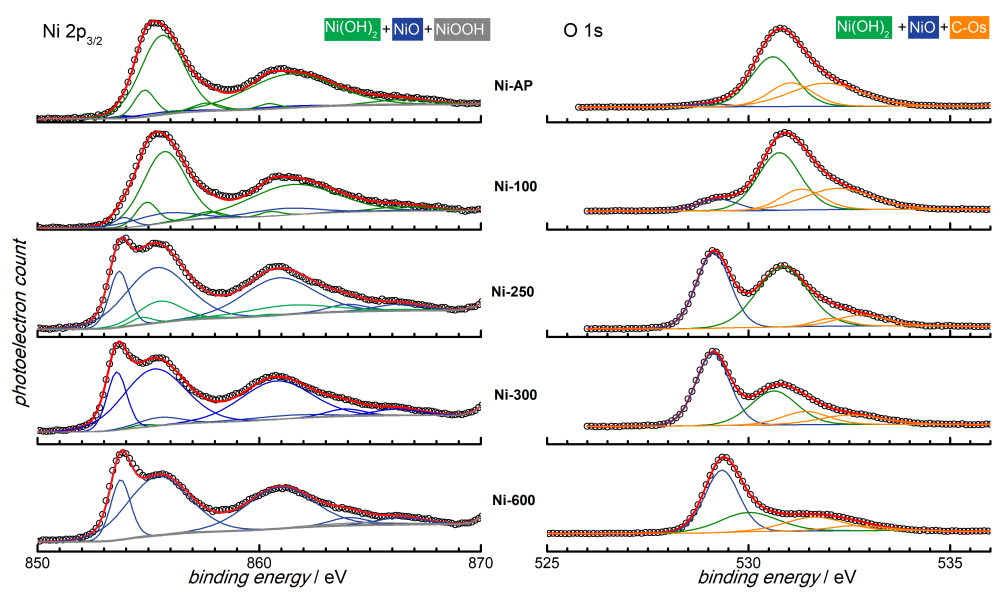

Figure S3: Ni p3/2 (lhs) and O 1s (rhs) XPS spectra of all samples. Fits to the spectra are plotted as red lines and individual fit components are plotted as lines in colors denoted. 
X-ray absorption spectroscopy 

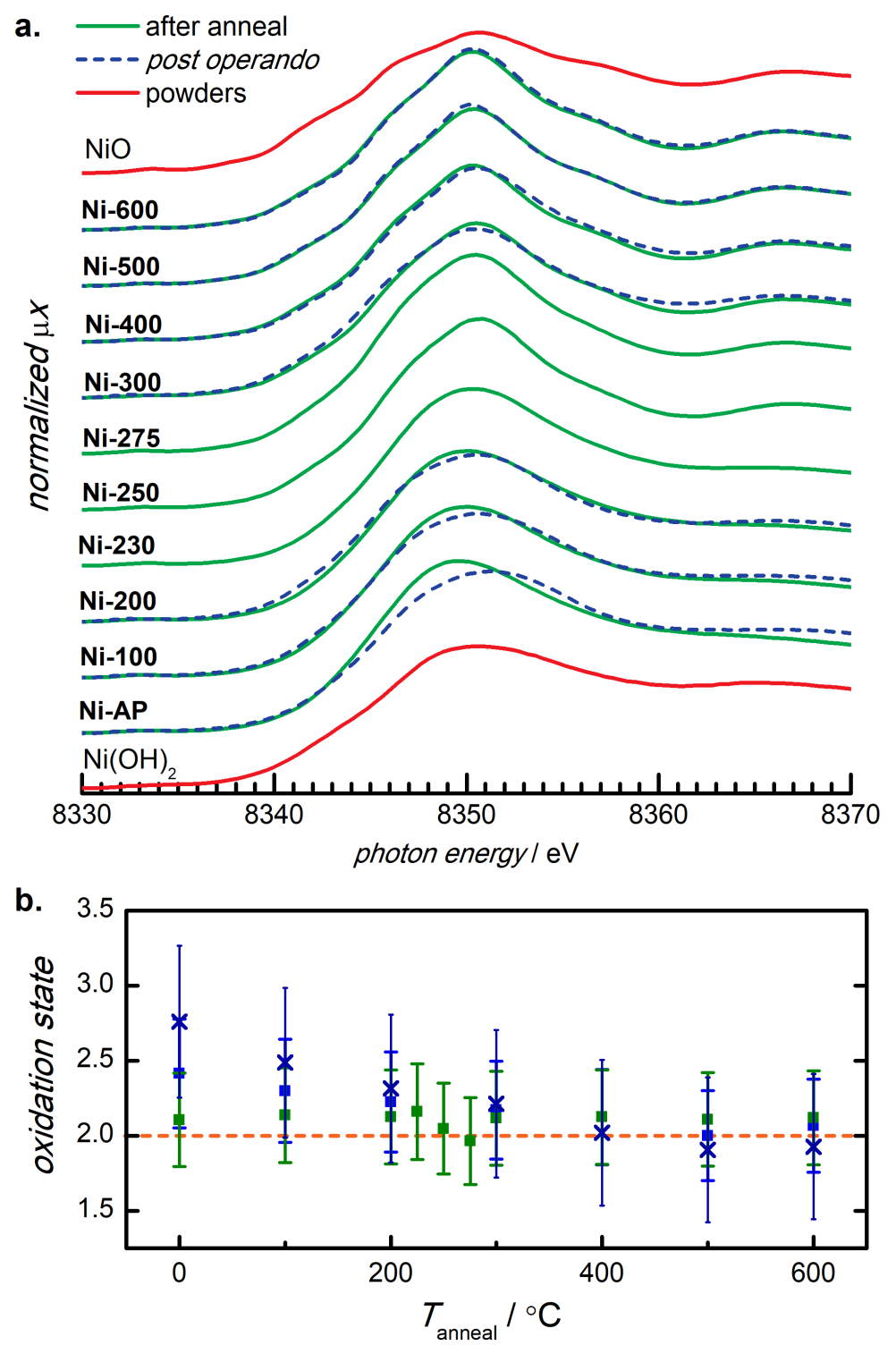

Figure S4: a. XANES spectra of samples Ni-AP through Ni-600 are plotted in green and postoperando series is plotted in blue dashed lines. Reference spectra of $\mathrm{Ni}(\mathrm{OH})_{2}$ and $\mathrm{NiO}$ are graphed in red. b. shows the oxidation state plotted against annealing temperature. Green and blue squares represent the oxidation states determined from XANES edge position for annealed and PO series, respectively. Blue crosses show the oxidation state of the PO series determined from oxygen bond distances. 

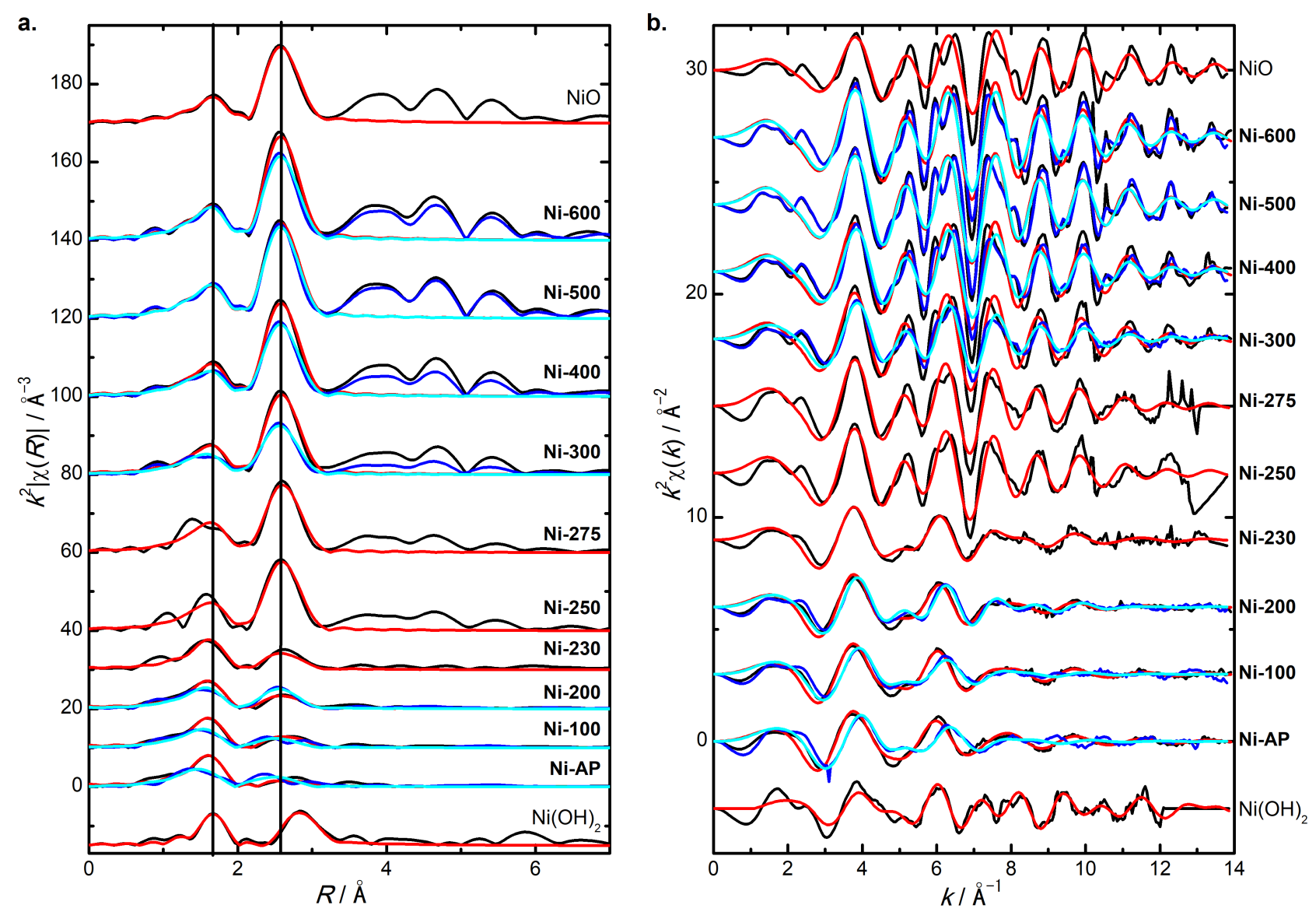

Figure S5: a. Fourier transform of the EXAFS signal and b. EXAFS signal for all samples. Data and fit for the annealed series are plotted in black and red, Data and fit for the PO series in dark blue and light blue. 


\section{Electrochemistry}
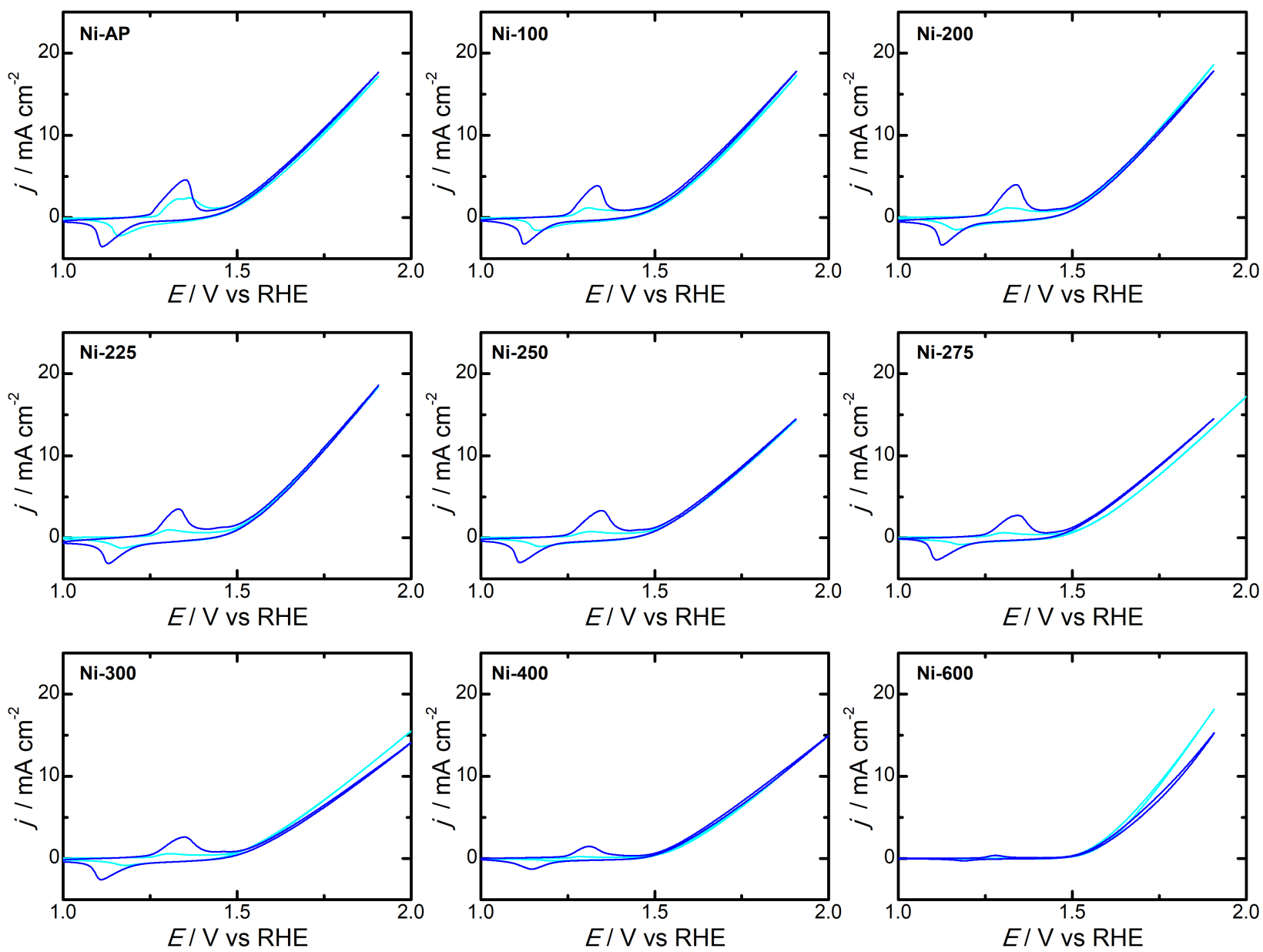

Figure S6: CVs of first run (light blue lines) and in steady state (dark blue lines). For each $T_{\text {anneal }}$ one representative sample it picked for clarity. 

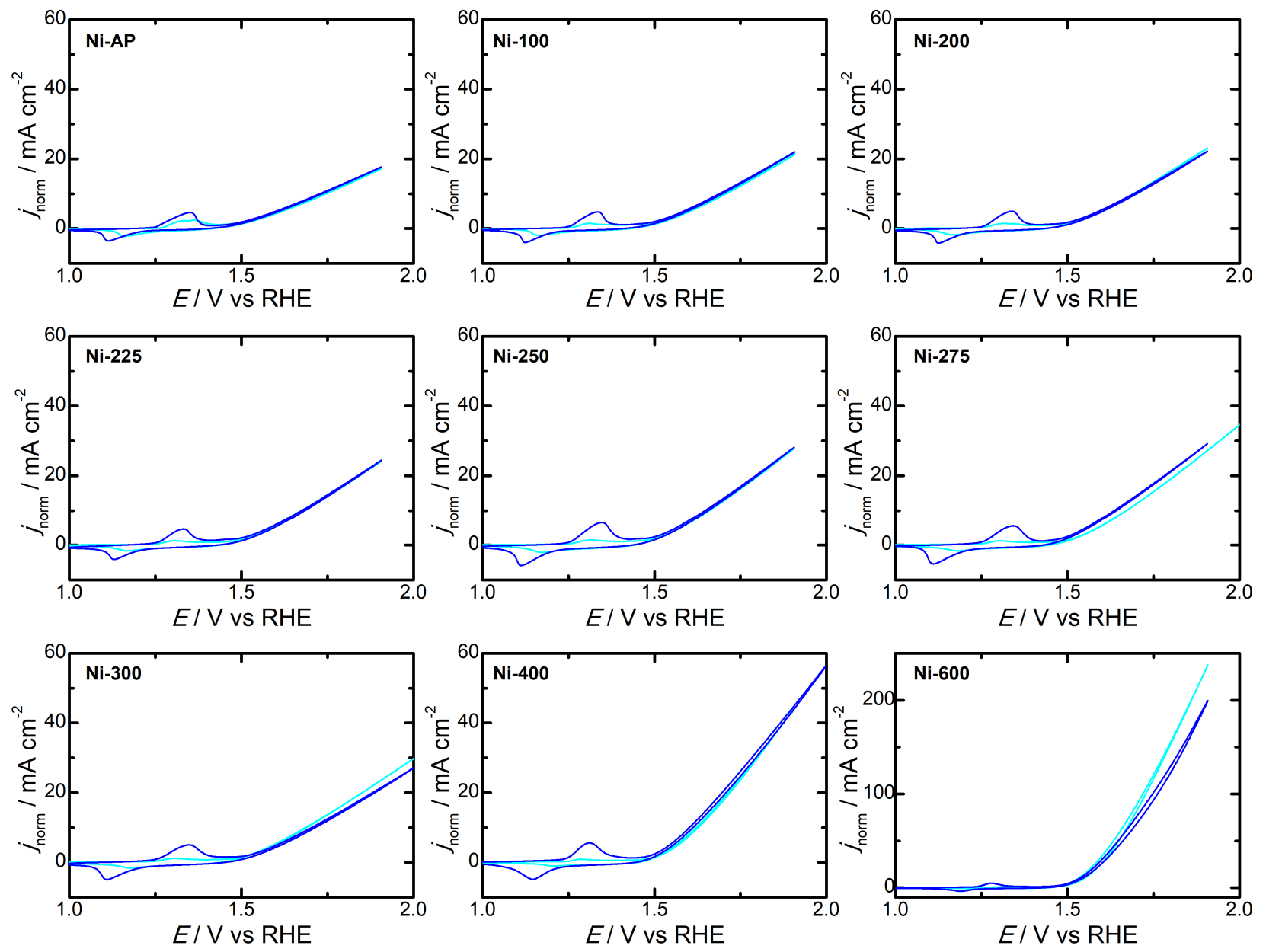

Figure S7: blue

CVs showing the current density normalized to the current passed under the redox wave, with respect to the Ni-AP sample, $j_{\text {norm }}$. The first run is plotted in light blue, steady state in dark blue. For each $T_{\text {anneal }}$ one representative sample it picked for clarity. 


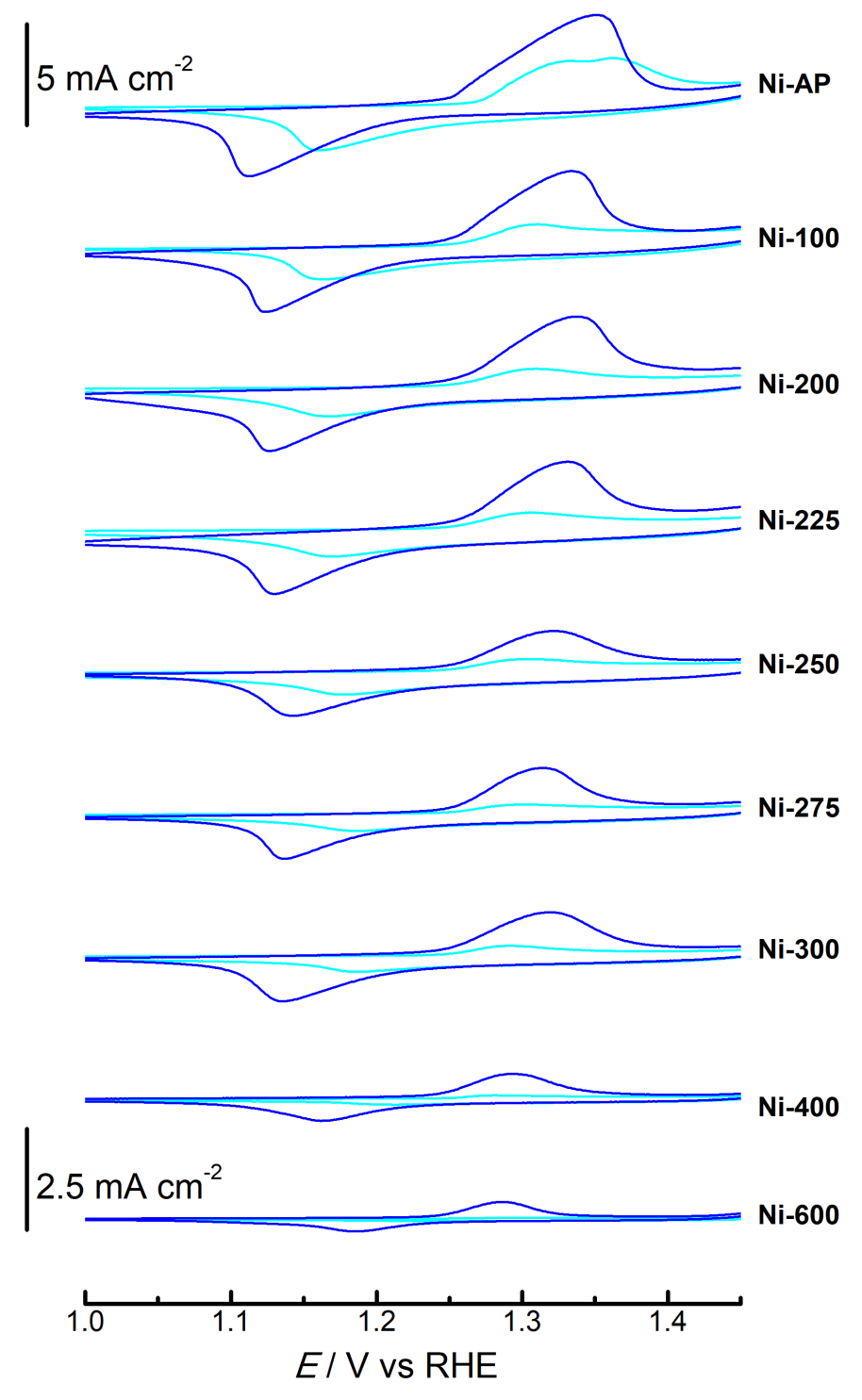

Figure S8: Emphasis on the Ni redox peaks of the pre-catalysis region of the CVs. Note the vertical scale for the Ni-600 sample is amplified for clarity. 

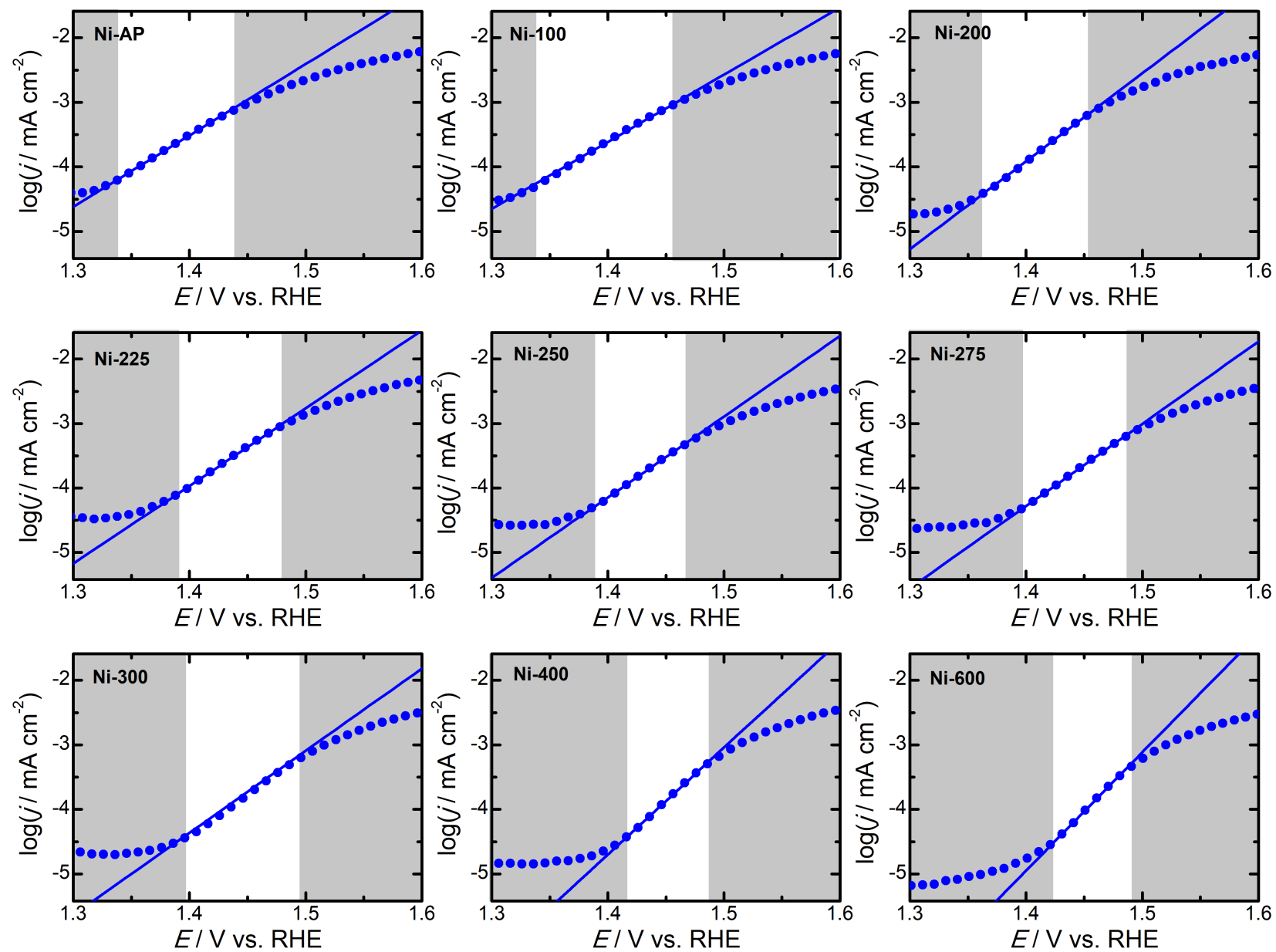

Figure S9: Representative steady-state current densities as a function of applied potential. Lines are linear fits used to determine the Tafel slope, data in the shaded regions excluded from fit. 

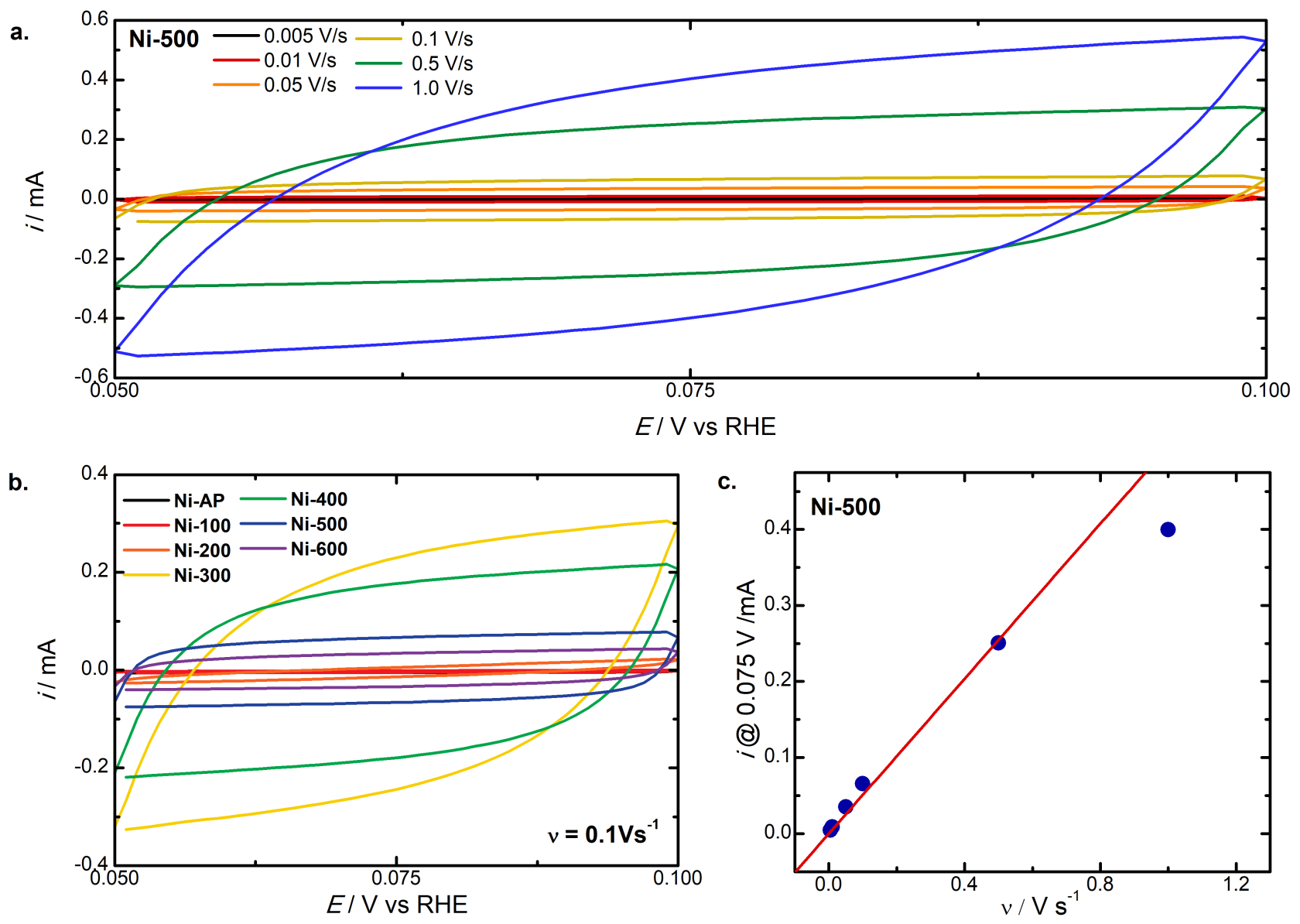

Figure S10: a. CVs of sample Ni-500 at sweep rates from $0.005 \mathrm{~V} / \mathrm{s}$ to $1 \mathrm{~V} / \mathrm{s}$. b. CVs for at a sweep rate of $0.01 \mathrm{~V} / \mathrm{s}$ for samples Ni-AP through Ni-600. c. current density at $0.075 \mathrm{~V} / \mathrm{mA}$ plotted against sweep rate. The red line is a linear fit to the linear range of the data to extract $C_{\mathrm{dl}}$. 


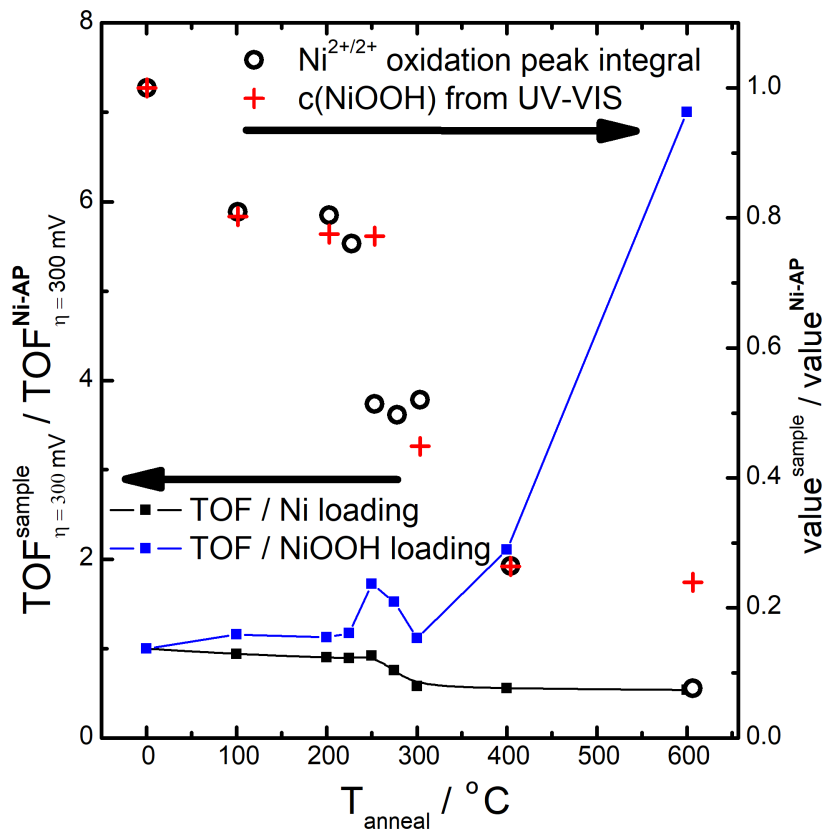

Figure S11: LHS axis: TOF normalized to Ni mass (black squares) and normalized to NiOOH concentration (blue squares). RHS axis: Fraction of $\mathrm{NiOOH}$ concentration normalized to $\mathrm{NiOOH}$ concentration of the Ni-AP sample determined from integration of the $\mathrm{Ni}^{2+/ 3+}$ oxidation peak (black open circles) and from UV-Vis (red crosses). The latter assumes the same film thickness for all samples, which is why results deviate from oxidation peak integration for high $T_{\text {anneal }}$ where the film thickness likely shrinks. 

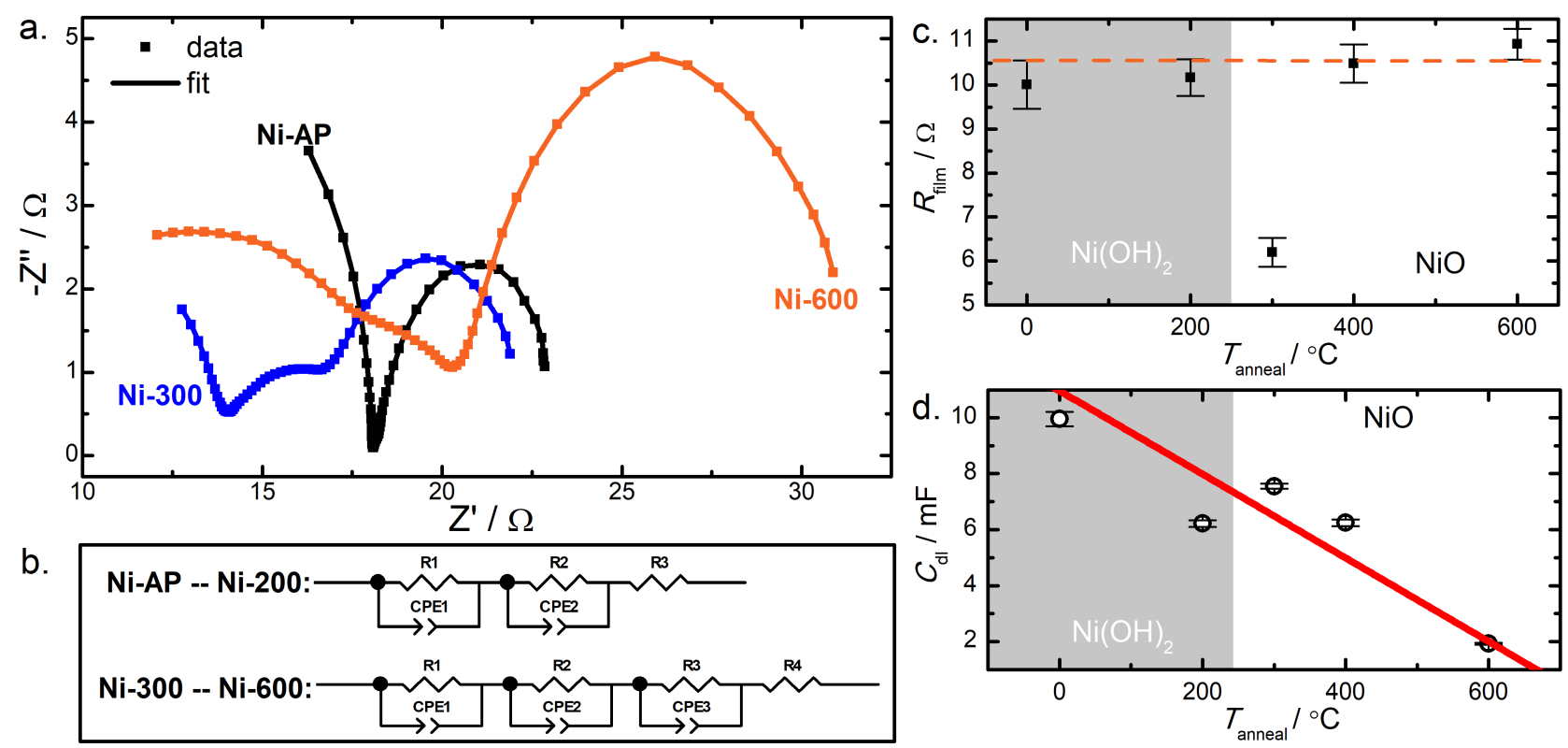

Figure S12: a. EIS spectra measured at a potential of $1.7 \mathrm{~V}$ vs RHE of Ni-AP, Ni-300, Ni-600 (symbols) with fits (lines) to models shown in b. The equivalent circuits in b. consist of elements $R_{1}$ and $C P E_{1}$ representing charge transfer resistance and double layer capacitance $C_{\mathrm{dl}}$, $R_{2}$ and $C P E_{2}$ representing film resistance $R_{\text {film }}$ and capacitance $C_{\text {film }}$, and $R_{3}\left(R_{4}\right)$ representing the uncompensated series resistance $R_{\mathrm{U}}$. For Ni-300 through Ni-600 we had to add elements $R_{3}$ and $C P E_{3}$ to correctly model the data, but cannot provide a physical interpretation for these elements. The fitted film resistance $R_{\text {film }}$ and double layer capacitance $C_{\mathrm{dl}}$ are plotted against $T_{\text {anneal }}$ in c. and d., respectively. The red line in $\mathrm{d}$. is a guide to the eye fit. 


\section{Electrochromism}

Steady-state electrochromism. The in situ UV-vis transmission spectra measured under conditions described in Fig. S14a are presented in Fig. S14b-d for samples Ni-100, Ni-300, and Ni600. Initially, all samples are transparent and for Ni-300 through Ni-600 their in situ spectra without applied potential mimic the FTO spectrum closely, while spectra at lower $T_{\text {anneal }}$ differ slightly from the FTO spectrum (Fig. S13). After a single CV measurement (step 2) is performed Ni-100 persists in a lightly colored state, while the other two samples experience little to no coloration. With applied potential all samples color further. However, sample coloration decreases with $T_{\text {anneal }}$ at the anodic oxidation peak $E_{\mathrm{p}, \mathrm{a}}$ (step 3), $1.9 \mathrm{~V}$ vs RHE (step 4), and $2.4 \mathrm{~V}$ vs RHE (step 5). The noise in steps 4 and 5 is attributed to oxygen bubbles formed under OER conditions, which scatter light. While spectra for Ni-100 change from convex to concave shape with applied potential, the spectra retain their convex shape for higher $T_{\text {anneal }}$. Furthermore, a marked increase in coloring is observed for all samples in step 5. Back at open current potential (OCP, step 6) the coloration reverts back to states similar to step 3. The discolored state is fully regained for all samples with regeneration (step 7, see Methods section). This regeneration is fully reproducible from any state of coloration. 


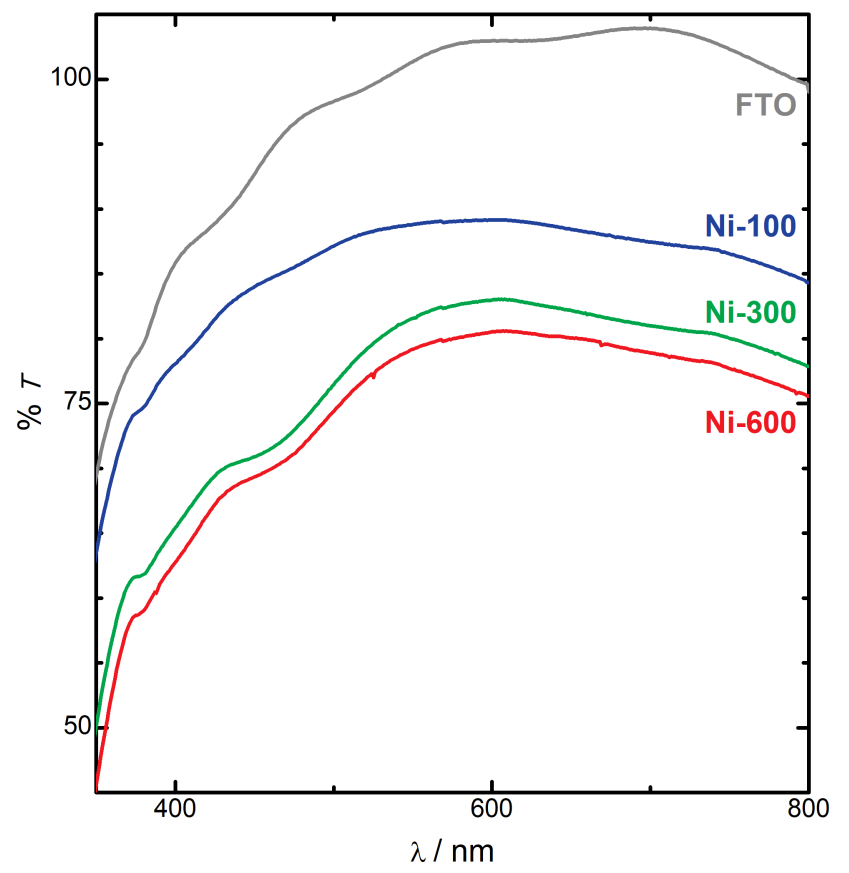

Figure S13: In situ spectra of Ni-100, Ni-300, and Ni-600 compared to blank FTO substrate. 
a.
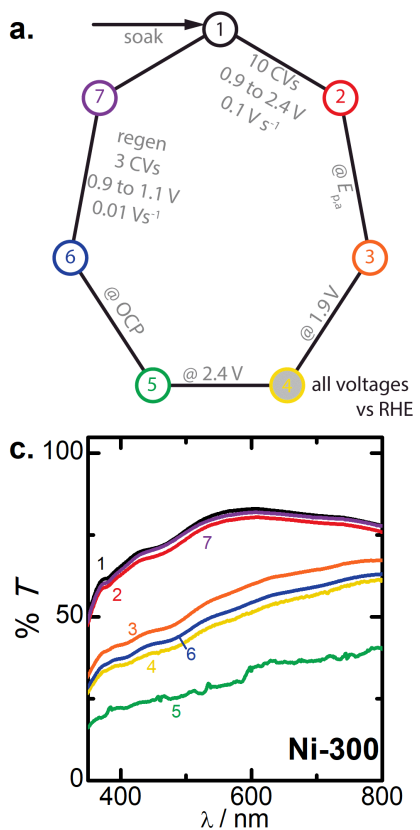
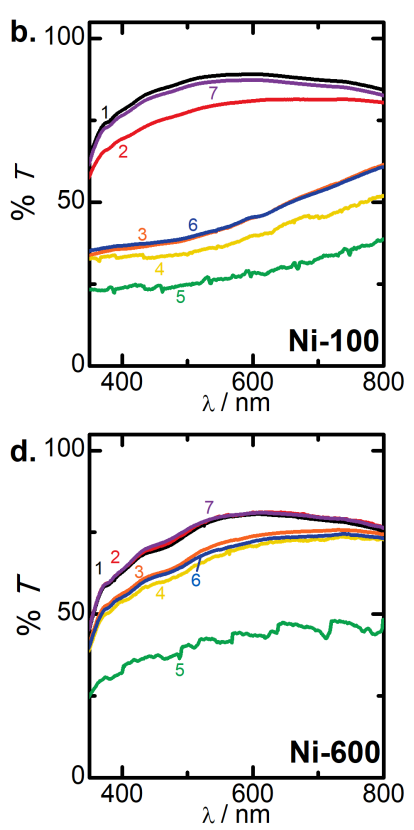

Figure S14: UV-Vis transmission spectra of samples annealed at b. $100{ }^{\circ} \mathrm{C}, \mathrm{c} .300{ }^{\circ} \mathrm{C}$, and d. $600{ }^{\circ} \mathrm{C}$ from $\lambda=400 \mathrm{~nm}$ to $800 \mathrm{~nm}$ taken in-situ in the electrochromic cell. $100 \%$ transmission is for the $\mathrm{KOH}$ filled cell at $800 \mathrm{~nm}$. Numbers signify the following steps in order: 1 immersed in $\mathrm{KOH}, 2$ after one CV, 3 at pre-oxidation peak potential, 4 at $1.9 \mathrm{~V}$ (vs RHE), 5 at $2.4 \mathrm{~V}$ (vs RHE), 6 at open current potential, 7 after regeneration cycle. a. shows a schematic of this measurement cycle. 

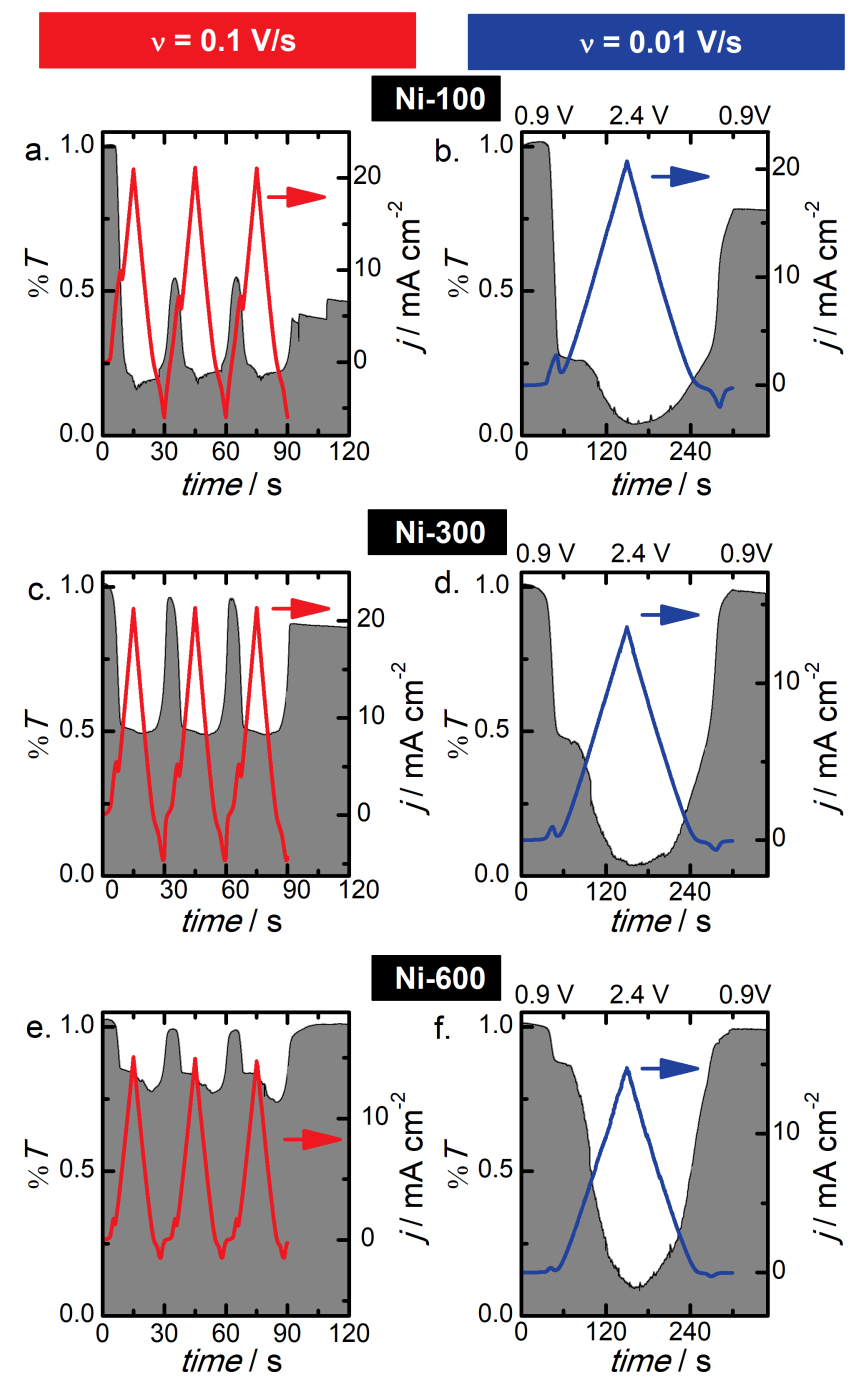

Figure S15: Transmission at $\lambda=450 \mathrm{~nm}$ plotted against time (black lines, lhs and bottom axis) and current density plotted against applied potential (gray lines, rhs and top axis) for samples annealed at a. and b. $100{ }^{\circ} \mathrm{C}$, c. and d. $300{ }^{\circ} \mathrm{C}$, and e. and f. $600^{\circ} \mathrm{C}$. a., c., and e. show three CVs at $0.1 \mathrm{~V} / \mathrm{s}$ sweep rate and b., d., and f. show single $\mathrm{CVs}$ at $0.01 \mathrm{~V} / \mathrm{s}$. 


\section{Tables}

Table S1: Constrained XPS fit parameters for each component. P1 and A1 refer to peak 1 position and area, respectively.

\begin{tabular}{llll} 
Constrained parameters & $\mathrm{NiO}$ & $\mathrm{Ni}(\mathrm{OH})_{2}$ & $\mathrm{NiOOH}$ \\
\hline \hline & & & \\
Peak 2 position $(\mathrm{eV})$ & $\mathrm{P} 1+1.7$ & $\mathrm{P} 1+0.8$ & $\mathrm{P} 1+0.7$ \\
Peak 2 area & $\mathrm{A} 1 \times 3.091$ & $\mathrm{~A} 1 \times 6.12$ & $\mathrm{~A} 1 \times 0.9$ \\
Peak 3 position $(\mathrm{eV})$ & $\mathrm{P} 1+7.2$ & $\mathrm{P} 1+2.8$ & $\mathrm{P} 1+1.06$ \\
Peak 3 area & $\mathrm{A} 1 \times 2.378$ & $\mathrm{~A} 1 \times 0.405$ & $\mathrm{~A} 1 \times 0.703$ \\
Peak 4 position $(\mathrm{eV})$ & $\mathrm{P} 1+10.3$ & $\mathrm{P} 1+5.6$ & $\mathrm{P} 1+1.84$ \\
Peak 4 area & $\mathrm{A} 1 \times 0.252$ & $\mathrm{~A} 1 \times 0.189$ & $\mathrm{~A} 1 \times 1.5$ \\
Peak 5 position $(\mathrm{eV})$ & $\mathrm{P} 1+12.6$ & $\mathrm{P} 1+6.6$ & $\mathrm{P} 1+3.17$ \\
Peak 5 area & $\mathrm{A} 1 \times 0.273$ & $\mathrm{~A} 1 \times 5.297$ & $\mathrm{~A} 1 \times 0.63$ \\
Peak 6 position $(\mathrm{eV})$ & & $\mathrm{P} 1+11.6$ & $\mathrm{P} 1+6.37$ \\
Peak 6 area & & $\mathrm{A} 1 \times 0.5$ & $\mathrm{~A} 1 \times 1.69$ \\
Peak 7 position $(\mathrm{eV})$ & & & $\mathrm{P} 1+9.75$ \\
Peak 7 area & & & $\mathrm{A} 1 \times 8.826$ \\
\hline
\end{tabular}


Table S2: Determined XPS fit parameters for each sample.

\begin{tabular}{|c|c|c|c|c|c|c|c|c|c|c|}
\hline Species & $\begin{array}{l}\mathrm{P} 1 \\
\text { pos } \\
/ \mathrm{eV}\end{array}$ & $\begin{array}{c}\mathrm{P} 1 \\
\text { area }\end{array}$ & $\begin{array}{c}\text { P1 } \\
\text { FWHM } \\
/ \text { eV }\end{array}$ & $\begin{array}{c}\text { P2 } \\
\text { FWHM } \\
/ \text { eV }\end{array}$ & $\begin{array}{c}\text { P3 } \\
\text { FWHM } \\
/ \text { eV }\end{array}$ & $\begin{array}{c}\text { P4 } \\
\text { FWHM } \\
/ \mathrm{eV}\end{array}$ & $\begin{array}{c}\text { P5 } \\
\text { FWHM } \\
/ \text { eV }\end{array}$ & $\begin{array}{c}\text { P6 } \\
\text { FWHM } \\
/ \text { eV }\end{array}$ & $\begin{array}{c}\text { P7 } \\
\text { FWHM } \\
/ \text { eV }\end{array}$ & Weight \\
\hline \multicolumn{11}{|c|}{ Ni-AP } \\
\hline $\mathrm{NiO}$ & 853.9 & 170.1 & 1 & 3.3 & 3.7 & 2 & 2.5 & & & $4 \%$ \\
\hline $\mathrm{Ni}(\mathrm{OH})_{2}$ & 854.8 & 1961.6 & 1.1 & 2.3 & 1.5 & 1.1 & 4.7 & 3 & & $94 \%$ \\
\hline $\mathrm{NiOOH}$ & 854.8 & 25 & 1.4 & 1.5 & 1.4 & 1.5 & 1.9 & 4 & 4.5 & $2 \%$ \\
\hline \multicolumn{11}{|c|}{ Ni-100 } \\
\hline $\mathrm{NiO}$ & 853.9 & 585.3 & 1 & 3.3 & 3.7 & 2 & 2.5 & & & $17 \%$ \\
\hline $\mathrm{Ni}(\mathrm{OH})_{2}$ & 854.9 & 1492 & 1.1 & 2.3 & 1.5 & 1.1 & 4.7 & 3 & & $83 \%$ \\
\hline $\mathrm{NiOOH}$ & 854.8 & 0.6 & 1.4 & 1.5 & 1.4 & 1.5 & 1.9 & 4 & 4.5 & $0 \%$ \\
\hline \multicolumn{11}{|c|}{ Ni-250 } \\
\hline $\mathrm{NiO}$ & 853.7 & 4171.2 & 1 & 3.3 & 3.7 & 2 & 2.5 & & & $79 \%$ \\
\hline $\mathrm{Ni}(\mathrm{OH})_{2}$ & 854.7 & 568.5 & 1.1 & 2.3 & 1.5 & 1.1 & 4.7 & 3 & & $20 \%$ \\
\hline $\mathrm{NiOOH}$ & 854.8 & 4 & 1.4 & 1.5 & 1.4 & 1.5 & 1.9 & 4 & 4.5 & $1 \%$ \\
\hline \multicolumn{11}{|c|}{ Ni-300 } \\
\hline $\mathrm{NiO}$ & 853.6 & 5884.1 & 1 & 3.3 & 3.7 & 2 & 2.5 & & & $89 \%$ \\
\hline $\mathrm{Ni}(\mathrm{OH})_{2}$ & 854.7 & 303.8 & 1.1 & 2.3 & 1.5 & 1.1 & 4.7 & 3 & & $9 \%$ \\
\hline $\mathrm{NiOOH}$ & 854.8 & 57.4 & 1.4 & 1.5 & 1.4 & 1.5 & 1.9 & 4 & 4.5 & $2 \%$ \\
\hline \multicolumn{11}{|c|}{ Ni-600 } \\
\hline $\mathrm{NiO}$ & 853.7 & 5291.9 & 1 & 3.3 & 3.7 & 2 & 2.5 & & & $95 \%$ \\
\hline $\mathrm{Ni}(\mathrm{OH})_{2}$ & 853.9 & 91.1 & 1.1 & 2.3 & 1.5 & 1.1 & 4.7 & 3 & & $1 \%$ \\
\hline $\mathrm{NiOOH}$ & 854.8 & 30 & 1.4 & 1.5 & 1.4 & 1.5 & 1.9 & 4 & 4.5 & $4 \%$ \\
\hline
\end{tabular}


Table S3: EXAFS fit parameters for all samples.

\begin{tabular}{lllllll} 
Sample & $N$ & $E_{0} / \mathrm{eV}$ & $R_{\mathrm{Ni}-\mathrm{O}} / \AA$ & $R_{\mathrm{Ni}-\mathrm{Ni}} / \AA$ & $\sigma^{2}(\mathrm{O}) / \AA^{2}$ & $\sigma^{2}(\mathrm{Ni}) / \AA^{2}$ \\
\hline \hline & & & & & & \\
Ni-AP & $4.7 \pm 0.4$ & $-4 \pm 1$ & $2.05 \pm 0.010$ & $3.08 \pm 0.028$ & $0.0067 \pm 0.001$ & $0.033 \pm 0.004$ \\
Ni-100 & $4.4 \pm 0.6$ & $-4 \pm 2$ & $2.05 \pm 0.0010$ & $3.06 \pm 0.018$ & $0.007 \pm 0.001$ & $0.024 \pm 0.002$ \\
Ni-200 & $4.8 \pm 0.8$ & $-4 \pm 2$ & $2.5 \pm 0.011$ & $3.03 \pm 0.019$ & $0.0084 \pm 0.002$ & $0.024 \pm 0.002$ \\
Ni-230 & $4.4 \pm 0.5$ & $-3 \pm 1$ & $2.05 \pm 0.012$ & $3.03 \pm 0.017$ & $0.0068 \pm 0.002$ & $0.020 \pm 0.002$ \\
Ni-250 & $5.6 \pm 0.8$ & $-2 \pm 1$ & $2.07 \pm 0.017$ & $2.99 \pm 0.011$ & $0.010 \pm 0.003$ & $0.010 \pm 0.001$ \\
Ni-275 & $5.8 \pm 0.9$ & $-2 \pm 1$ & $2.08 \pm 0.017$ & $2.99 \pm 0.012$ & $0.009 \pm 0.003$ & $0.010 \pm 0.002$ \\
Ni-300 & $5.6 \pm 0.5$ & $-3 \pm 1$ & $2.08 \pm 0.010$ & $2.97 \pm 0.007$ & $0.009 \pm 0.002$ & $0.009 \pm 0.0008$ \\
Ni-400 & $5.7 \pm 0.4$ & $-3 \pm 1$ & $2.08 \pm 0.010$ & $2.96 \pm 0.006$ & $0.008 \pm 0.002$ & $0.008 \pm 0.0007$ \\
Ni-500 & $6.0 \pm 0.4$ & $-3 \pm 1$ & $2.08 \pm 0.009$ & $2.96 \pm 0.005$ & $0.009 \pm 0.002$ & $0.008 \pm 0.0007$ \\
Ni-600 & $5.9 \pm 0.5$ & $-3 \pm 1$ & $2.08 \pm 0.011$ & $2.96 \pm 0.007$ & $0.008 \pm 0.002$ & $0.007 \pm 0.0008$ \\
\hline Ni-AP-PO & $4.3 \pm 0.8$ & $-4 \pm 2$ & $1.98 \pm 0.02$ & $2.93 \pm 0.03$ & $0.013 \pm 0.004$ & $0.027 \pm 0.004$ \\
Ni-100-PO & $4.2 \pm 0.6$ & $-4 \pm 1$ & $2.0 \pm 0.02$ & $2.96 \pm 0.02$ & $0.012 \pm 0.003$ & $0.028 \pm 0.003$ \\
Ni-200-PO & $4.1 \pm 0.3$ & $-3 \pm 1$ & $2.02 \pm 0.01$ & $2.97 \pm 0.01$ & $0.010 \pm 0.002$ & $0.018 \pm 0.001$ \\
Ni-300-PO & $4.7 \pm 0.3$ & $-3 \pm 1$ & $2.04 \pm 0.01$ & $2.95 \pm 0.01$ & $0.011 \pm 0.002$ & $0.011 \pm 0.008$ \\
Ni-400-PO & $5.1 \pm 0.4$ & $-2 \pm 1$ & $2.06 \pm 0.01$ & $2.96 \pm 0.01$ & $0.010 \pm 0.002$ & $0.009 \pm 0.0008$ \\
Ni-500-PO & $5.6 \pm 0.4$ & $-3 \pm 1$ & $2.07 \pm 0.01$ & $2.96 \pm 0.01$ & $0.008 \pm 0.002$ & $0.008 \pm 0.0007$ \\
Ni-600-PO & $5.4 \pm 0.4$ & $-3 \pm 1$ & $2.07 \pm 0.01$ & $2.96 \pm 0.01$ & $0.008 \pm 0.002$ & $0.008 \pm 0.0008$ \\
\hline
\end{tabular}

Table S4: EIS fit parameters for all samples, with $R_{\mathrm{ct}}$ the charge transfer resistance, $C_{\mathrm{dl}}$ the double layer capacitance, $R_{\text {film }}$ the film resistance, $C_{\text {film }}$ the film capacitance, and $R_{\mathrm{S}}$ the series resistance. We cannot provide a physical interpretation for $R_{2}$ and $C_{2}$, however introducing those elements in the equivalent circuit was necessary to obtain a good fit for samples Ni-300-Ni-600.

\begin{tabular}{llllll} 
sample & $R_{\mathrm{ct}} / \Omega$ & $C_{\mathrm{dl}} / \mathrm{F}$ & $R_{\mathrm{film}} / \Omega$ & $C_{\mathrm{film}} / \mathrm{F}$ & $R_{\mathrm{S}} / \Omega$ \\
\hline Ni-600 & $11.07 \pm 0.06$ & $1.9 \cdot 10^{-3} \pm 3 \cdot 10^{-5}$ & $10.9 \pm 0.35$ & $2.9 \cdot 10^{-7} \pm 5 \cdot 10^{-8}$ & $7.9 \pm 0.2$ \\
Ni-400 & $3.9 \pm 0.4$ & $6.3 \cdot 10^{-3} \pm 1 \cdot 10^{-4}$ & $10.5 \pm 0.4$ & $2.0 \cdot 10^{-7} \pm 2 \cdot 10^{-8}$ & $7.9 \pm 0.2$ \\
Ni-300 & $5.02 \pm 0.05$ & $7.5 \cdot 10^{-3} \pm 8 \cdot 10^{-5}$ & $6.2 \pm 0.3$ & $3.3 \cdot 10^{-7} \pm 3 \cdot 10^{-8}$ & $7.9 \pm 0.2$ \\
Ni-200 & $7.72 \pm 0.06$ & $6.2 \cdot 10^{-3} \pm 1 \cdot 10^{-4}$ & $10.2 \pm 0.4$ & $2.8 \cdot 10^{-8} \pm 2 \cdot 10^{-9}$ & $8.2 \pm 0.4$ \\
Ni-AP & $5.3 \pm 0.05$ & $9.9 \cdot 10^{-3} \pm 3 \cdot 10^{-4}$ & $10.0 \pm 0.5$ & $3.3 \cdot 10^{-8} \pm 3 \cdot 10^{-9}$ & $8.1 \pm 0.5$ \\
\hline sample & $R_{3} / \Omega$ & $C_{3} / \mathrm{F}$ & & & \\
\hline Ni-600 & $1.8 \pm 0.2$ & $1.7 \cdot 10^{-4} \pm 3 \cdot 10^{-5}$ & & & \\
Ni-400 & $5.7 \pm 0.6$ & $0.015 \pm 0.002$ & & & \\
Ni-300 & $3.53 \pm 0.05$ & $2.0 \cdot 10^{-3} \pm \cdot 10^{-4}$ & & &
\end{tabular}


Table S5: Coloring rates $r$ (in s ${ }^{-1}$ ) and coloration times $\tau$ (in s) at different applied potentials $E$

\begin{tabular}{llll} 
sample & \multicolumn{3}{c}{$\boldsymbol{r}(\tau)$} \\
& $E=E_{\mathrm{p}, \mathrm{a}}$ & $E=1.9 \mathrm{~V}$ & $E=2.4 \mathrm{~V}$ \\
\hline $\mathbf{N i}^{2}-\mathbf{1 0 0}^{a}$ & $0.3(3.2)$ & $1.7(0.6)$ & $2.5(0.4)$ \\
Ni-300 $^{b}$ & $0.2(4.3)$ & $1.4(0.7)$ & $2.0(0.5)$ \\
Ni-600 $^{c}$ & $0.5(2.2)$ & $3.3(0.3)$ & $5(0.2)$ \\
\hline${ }^{a} E_{\mathrm{p}, \mathrm{a}}=1.38 \mathrm{~V}$ vs RHE; \\
${ }^{b}$ & $E_{\mathrm{p}, \mathrm{a}}=1.33 \mathrm{~V}$ vs RHE; \\
${ }^{c} E_{\mathrm{p}, \mathrm{a}}=1.28 \mathrm{~V}$ vs RHE &
\end{tabular}




\section{References}

(1) Trotochaud, L.; Young, S. L.; Ranney, J. K.; Boettcher, S. W. Nickel-Iron Oxyhydroxide Oxygen-Evolution Electrocatalysts: The Role of Intentional and Incidental Iron Incorporation. J. Am. Chem. Soc. 2014, 136, 6744-6753.

(2) Trudel, S.; Li, G.; Zhang, X.; Hill, R. H. Positive and Negative Lithography by Photochemical Metalorganic Deposition from Metal 2-ethylhexanoates. J. Photopolym. Sci. Tec. 2006, 19, $467-475$.

(3) Smith, R. D. L.; Prévot, M. S.; Fagan, R. D.; Trudel, S.; Berlinguette, C. P. Water Oxidation Catalysis: Electrocatalytic Response to Metal Stoichiometry in Amorphous Metal Oxide Films Containing Iron, Cobalt, and Nickel. J. Am. Chem. Soc. 2013, 135, 11580-11586.

(4) Smith, R. D. L.; Prévot, M. S.; Fagan, R. D.; Zhang, Z.; Sedach, P. A.; Siu, M. K. J.; Trudel, S.; Berlinguette, C. P. Photochemical Route for Accessing Amorphous Metal Oxide Materials for Water Oxidation Catalysis. Science 2013, 340, 60-63.

(5) Patterson, A. L. The Scherrer Formula for X-Ray Particle Size Determination. Phys. Rev. 1939, 56, 978-982.

(6) Langford, J. I.; Wilson, A. J. C. Scherrer after sixty years: A survey and some new results in the determination of crystallite size. J. Appl. Crystallogr. 1978, 11, 102-113.

(7) Tauc, J. Optical properties and electronic structure of amorphous Ge and Si. Mater. Res. Bull. 1968, 3, $37-46$.

(8) Ravel, B.; Newville, M. ATHENA, ARTEMIS, HEPHAESTUS: data analysis for X-ray absorption spectroscopy using IFEFFIT. J. Synchrotron Radiat. 2005, 12, 537-541.

(9) Kraft, S.; Stümpel, J.; Becker, P.; Kuetgens, U. High resolution x-ray absorption spectroscopy with absolute energy calibration for the determination of absorption edge energies. Rev. Sci. Instrum. 1996, 67, 681-687. 
(10) Mustre de Leon, J.; Rehr, J. J.; Zabinsky, S. I.; Albers, R. C. Ab initio curved-wave x-rayabsorption fine structure. Phys. Rev. B 1991, 44, 4146-4156.

(11) Rehr, J. J.; Albers, R. C. Scattering-matrix formulation of curved-wave multiple-scattering theory: Application to x-ray-absorption fine structure. Phys. Rev. B 1990, 41, 8139-8149.

(12) Biesinger, M. C.; Payne, B. P.; Lau, L. W. M.; Gerson, A.; Smart, R. S. C. X-ray photoelectron spectroscopic chemical state quantification of mixed nickel metal, oxide and hydroxide systems. Surf. Interface Anal. 2009, 41, 324-332.

(13) Klaus, S.; Cai, Y.; Louie, M. W.; Trotochaud, L.; Bell, A. T. Effects of Fe Electrolyte Impurities on $\mathrm{Ni}(\mathrm{OH})_{2} / \mathrm{NiOOH}$ Structure and Oxygen Evolution Activity. J. Phys. Chem. C 2015, 119, $7243-7254$.

(14) Noam, E.; Eliezer, G. Physical Electrochemistry: Fundamentals, Techniques, and Applications. Wiley-VCH, Weinheim 2018,

(15) Manjunatha, K. N.; Paul, S. Investigation of optical properties of nickel oxide thin films deposited on different substrates. Appl. Surf. Sci. 2015, 352, 10 - 15.

(16) Nalage, S.; Chougule, M.; Sen, S.; Joshi, P.; Patil, V. Sol-gel synthesis of nickel oxide thin films and their characterization. Thin Solid Films 2012, 520, 4835 - 4840.

(17) Itapu, S.; Borra, V.; Mossayebi, F. A Computational Study on the Variation of Bandgap Due to Native Defects in Non-Stoichiometric NiO and Pd, Pt Doping in Stoichiometric NiO. J. Phys. Condens. Matter 2018, 3. 